"A multiagent game theoretical approach to adverse selection in corporate financing"

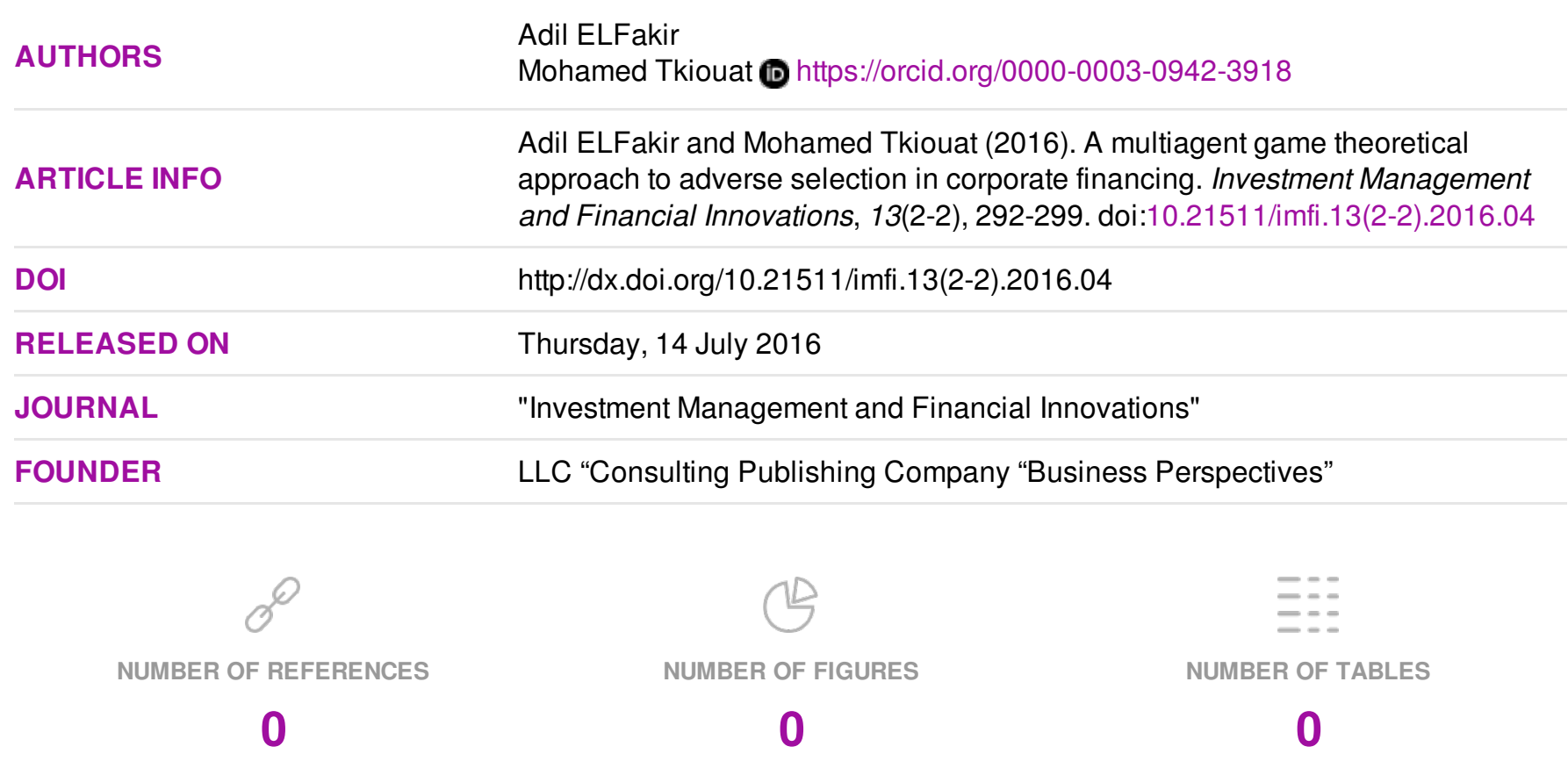

(C) The author(s) 2022. This publication is an open access article. 
Adil ELFakir (Morocco), Mohamed Tkiouat (Morocco)

\title{
A multiagent game theoretical approach to adverse selection in corporate financing
}

\author{
Reducing asymmetric information in Mudaraba contracts by developing Adverse selection indices
}

\begin{abstract}
In this research the authors tried to solve the adverse selection problem in the Mudaraba contracts with respect to the projects privately known prospects. The authors introduced a model of two contracts characterized by an adverse selection index for each contract. They have managed to find that a case of market breakdown can occur because the efficient agent might mimic the inefficient agent. The authors, then, managed to develop a 'Mimicking Likelihood Index' whereby one can infer whether a type of an agent has a tendency to mimic the other type. In the same context, the authors developed a "Relative Adverse Selection" index to measure which type of agents has more tendencies to select a specific type of contracts. These findings should help Islamic financial institutions in their agent selection process and hedge its risky Mudaraba contracts.
\end{abstract}

Keywords: Mudaraba, perfect cross subsidization, market breakdown, relative adverse selection, due diligence, adverse selection, Islamic venture capitalist.

JEL Classification: C700.

\section{Introduction}

The central idea in the concept of Mudarib is that two parties, one with capital and the other with know-how, get together to carry out a project. The financier provides the capital and plays no further part in the project. Specifically, he does not interfere in its execution, which is the exclusive province of the entrepreneur. If the project ends in profit, they share the profit in a pre-arranged proportion. If it results in a loss the entire loss, is borne by the financier, and the entrepreneur gains no benefit out of his effort, which was his part of the investment. There are many variations of this simple model but this is the basic concept (Gafoor, 2001). In this type of financing, the Mudarib may possess private information that he can use to have some informational gains. This kind of problems is called adverse selection. Our motivation starts from the fact that Mudaraba financing, due to its risks, is of less practice despite its overwhelming profits in case of success. In the process of this problem reduction, we have tried to develop the Tirole's (2010) projects privately known prospects model in three different ways. First, we extended the model using a menu of two different contracts. Second, we allowed for specific probabilities of contract success given a specific agent type. Third, we tried to make the model Shari'a compliant. Fourth, we developed adverse selection indices; and, fifth, we combined

\footnotetext{
(C) Adil ELFakir, Mohamed Tkiouat, 2016.

Adil ELFakir, Lecturer of Corporate Finance and Investment at Cardiff Metropolitan University (SiST off-campus Morocco), Lecturer of Management Accounting and Industrial Economics at IIHEM, Rabat, Morocco.

Mohamed Tkiouat, Professor of Industrial Economics and Game Theory, Department of Industrial Engineering, IFE-Lab, Laboratoty of Research in Applied Mathematics (LERMA), Mohamadia School of Engineers, Rabat, Morocco.
}

our indices with Shari'a compliant due diligence to minimize adverse selection.

This research will proceed as follows: in section 1 , we provide a literature review about conventional system and Islamic financial system. In section 2, we present our methodology. In section 3 , we present our results and discussions. The final section concludes.

\section{Literature review}

\subsection{Research related to the conventional banking} system. In his book "The theory of corporate finance", Tirole (2010) describes an adverse selection model in which the agent has an informational advantage over the investors about the prospects of their projects. $\mathrm{He}$ described two situations of paramount importance: market breakdown where financing does not occur, because inefficient entrepreneurs cannot separate from efficient ones and cross subsidization where, when financing occurs, efficient entrepreneurs lose and inefficient entrepreneurs gain. In our analysis, we show that there exist more than one market breakdown using a two contract strategy. In fact, even the efficient entrepreneurs might pool with inefficient ones creating a situation where nobody gets funding. We also show that given certain specific probabilities we can create a situation where gains from asymmetric information can perfectly subsidize losses. We refer to this case as "perfect cross subsidization". Moreover, cross subsidization is not a necessity, as we might have a case where both types lose (gain) from asymmetric information. Tirole (2010) has introduced an adverse selection index, but did not mention how it can be used to focus on "mimicking Types". We derived a "Mimicking Likelihood Index" and "Relative Adverse selection" for this purpose.

To overcome of adverse selection problem, the use of dissipative signals is of great importance. We list the following: 
The first is certification. Tirole (2010) shows, that as long as the certification cost is less than the adverse selection index, the efficient entrepreneurs will be willing to certify their issue. However, this cost can be high if the certifier is risk averse and lacks diversification (Chemmanur and Fulghieri, 1994).

The second is collateral which can be used by efficient agents as a signaling mechanism of their type. This signaling method is consistent with previous researches as in Besanko and Thakor (1987). Other researches also claim that banks can use collateral in debt contracts to overcome information asymmetries, in particular, arising from ex-ante adverse selection (Berger et al., 2011). Collateral as a self selection mechanism was studied in Bester (1985). The paper assumes that banks decide upon the rate of interest and the collateral of their creditors simultaneously rather than separately. Therefore, it becomes possible to use different contracts as a self-selection mechanism.

The third mechanism is low job protection. This mechanism not only can be made similar to a high pledged collateral, i.e., a confident manager will demand a high reward in case of success, but also signs for a low job protection in case of failure. This is consistent with previous research as in Subramanian et al. (2002). However, and inconsistent with these findings, the use of warranties (collateral) in the conventional system seems to be no more than a limited control mechanism to overcome the agency problem Padilla and Pagano(1997).

The fourth mechanism is short-term maturities. Using short-term contracts may be used as signal for the quality of the entrepreneur. Padilla and Pagano (1997) show that efficient entrepreneurs use shortterm contracting to show that, they are confident about the prospects of their projects. This is consistent with other research. In fact, Landier and Thesmar (2003) show that in a competitive credit market, optimistic (confident) entrepreneurs opt for shorter debt maturities than realistic entrepreneurs, to signal that they are unlikely to face difficult circumstances.

The fifth mechanism is payout policy. Bernheim and Wantz (1992) show that dividends are motivated by signaling concerns rather than a disposal of free cash. However, we must consider the payout policy in conjunction with the incentive policy being put in place. For example, a dividend policy that rewards the manager for long-term achievement will make the manager less motivated to distribute dividend in a short term.

The sixth mechanism is under pricing. This occurs when the entrepreneur reduce their compensation in order to obtain financing. According to Tirole
(2010), when the two types become more similar, the efficient borrower must underprice more (i.e., accept a lower compensation in order to make the issue unappealing to an inefficient borrower).

The seventh mechanism is diversification and incomplete insurance. Brealey et al. (1977) show that under symmetric information the efficient borrower gets full insurance using a diversified portfolio and the investor bears all the risk. However, under asymmetric information, efficient borrowers are willing to bear more risk in order to demonstrate their confidence in the project's prospects.

The last mechanism is information sharing: previous work has shown how information sharing promotes credit market efficiency with benefits for the whole economy.

In fact, credit bureaus have been shown to decrease adverse selection (Pagaon and Jappelli, 1993) and increase efforts from borrowers (Padilla and Pagano, 1997). At the same time, information sharing may be used to reduce competition between banks (Gehrig and Stenbacka, 2007). Also, information sharing is more likely if borrower mobility is higher (Pagaon and Jappelli, 1993) and if asymmetric information problems are more important (Brown and Zehnder, 2010). Empirical research has shown that information sharing is correlated with higher access to credit (Pagaon and Jappelli, 1993), especially in developing countries with inefficient creditor rights (Djankov et al., 2007; Brown et al., 2009), but lower lending to low-quality borrowers (Hertzberg et al., 2011). However, some negative points arise from information sharing. Gehrig and Stenbacka (2007), show that information sharing reduces the returns from establishing banking relationships. It, therefore, weakens banks competition. Therefore, information sharing is a mechanism to redistribute surplus from talented entrepreneurs to banks, but, due to the implied anticompetitive effects, reduce the social returns of information sharing.

\subsection{Research related to Islamic venture capital.} Few models have been developed to solve adverse selection problem and information asymmetry in Islamic venture capital case (Mehri and Jouaber 2012). One of the main reasons is the weakness of practice of Mudaraba in Islamic Finance due to misreporting risk. According to Al-Suwailem (2006), misreporting of risk happens when the agent announces losses, while the project is making profits. Based on a Survey by Khalil et al. (2002), misreporting is the prime reason why Islamic banks are not applying Mudaraba on the asset side of their balance sheets. Van Greuning and Iqbal (2008) explain that the significant investment risk of 
Mudaraba is reflected in its small share in total assets.

One work by Mehri and Jouaber (2012) has studied the usefulness of the sharing ratio $\Omega$ retained by the Islamic venture capitalist (IVC) in tackling the adverse selection. Their results were the following:

1. High entrepreneur's risk aversion reduces the chance of choosing an inefficient type and increases $\Omega$.

2. High IVC's risk aversion reduces the chance of selecting a low type agent, but reduces $\Omega$.

3. $\Omega$ is lower if the project is managed by an efficient type.

4. An efficient agent accepts a higher $\Omega$ than an inefficient agent.

5. Agent's management fees are positively related to $\Omega$ regardless of the type of the agent's type.

This study is limited by the fact that:

1. IVC can detect the quality of the project which is not always possible. In fact, the agent because of his informational comparative advantage can have more knowledge about the projects than the IVC.

2. Information asymmetry is based only on the type of the entrepreneur, while it can be related to many other parameters (i.e., agents related parameters such as the degree of motivation of the entrepreneur towards the project, learning capacity, short-term or long-term oriented agent and/or exogenous parameters: economic state, market competitiveness).

These problems are related to the inability of the banks to detect the true return on investment (Williamson, 1986). The agent has a tendency to overestimate the quality of his activities (Al-Jarhi and Iqbal, 2001). For example, he can overestimate the probability of success of his project in order to get financing (Manove et al., 2001) or he can declare, ex-ante, a higher expected profit in order to induce the IVC to reduce its profit sharing ratio.

In order to solve the selection adverse problem, some researchers propose that a contract with a predetermined profit sharing ratio induces the entrepreneurs to behave honestly (Khan, 1985). This is due to the fact that the return of their project depends on their actions (Khan, 1985). In order to solve the agency problem, Khan (1985) proposes the offering of performance based shares and reserves plans when profits areachieved.

In fact one of the critical issues is to determine the sharing ratio that will solve the adverse selection. These methods are, therefore, considered as mechanisms of compensation rather than prevention methods against adverse selection.
Bacha (1997) proposes that a fair distribution of profit and risk can be achieved through some financing mechanisms like "Mezzanine" and "Vertical Strip Financing".

Since mezzanine financing is usually provided to the borrower very quickly with little due diligence on the part of the lender and little or no collateral on the part of the borrower, this type of financing is aggressively priced, with the lender seeking a return in the $20 \%-30 \%$ range.

These solutions can reduce the agency problem, but may not eliminate all the risks related to a project.

Also, since mezzanine financing is usually provided to the borrower very quickly with little due diligence on the part of the lender and little or no collateral, this type of financing command a very high price.

A higher degree of vigilance and precautions is required from the IVC and the entrepreneur.

Also, these methods can be useful only after the selection of the entrepreneur which does not solve the adverse selection problem. Karim (2015) proposes that the entrepreneur's participation in the capital and the submission of a warranty can resolve the adverse selection problem. In our case, we are dealing with Mudaraba financing in which case there is no participation in the capital by the entrepreneur. Also the delivery of a warranty against performance is not permissible under the Shari'a Law (AAOIFI, 2003). However, the recourse to a warranty is permissible if there is a proof of negligence or nonrespect of the contract terms by the entrepreneur.

Shaikh (2011) argument is that the agency problem is based on an unfair distribution of returns if the project fails.

Taking into consideration the risks related to a project, the IVC may demand a higher sharing ratio. This, however, may result in less motivation of the entrepreneur and therefore a lower project.

In dealing with moral hazards in Mudaraba financing, Yousfi (2013) suggested higher incentives in case the project is risky and lower compensation schemes in case the project is not risky.

\subsection{Comparison of capital risk financing under} Islamic banking and conventional banking. The practice of profit and loss sharing is well established in both conventional and Islamic banking. It was even used before Islam (Mutalip and Lutfi, 2009). However, there exist some points of differences: first, the problem of adverse selection is more important in Islamic Mudaraba than in Musharaka (partnership) or conventional banking, as the entrepreneur does not contribute with a capital (Mehri and Jouaber, 2012). Second, the Islamic 
bank does not intervene in the project and, therefore, assumes all losses in case the project fails (Mehri and Jouaber, 2012). Third, from the above, we conclude that the entrepreneur is induced to undertake some decisions that serve only his own interests. Chapra and Khan (2000) consider that Mudaraba is the most risky in comparison with the rest of modes of financing. Fourth, the projects undertaken by the agent have to be in conformity with the Shari'a. This, however, is not a requirement in conventional finance. The notion of profit sharing is based on a negotiated and pre-determined rate, while, in the conventional system, it is based on the principle of carried interest. Gompers and Lerner (1999) inform that $81 \%$ of the conventional banks use a carried interest between $20 \%$ and $21 \%$.

\section{The model}

Our model will cover the symmetric and the assymetric case. But, before we proceed, we should lay down the foundation for the model with the mathematical notations:

$p_{s g}^{1}$ : probability of success of contract 1 given that it is chosen by the efficient entrepreneur;

$p_{s g}^{2}$ : probability of success of contract 2 given that it is chosen by the efficient entrepreneur;

$p_{s b}^{1}$ : probability of success of contract 1 given that it is chosen by the inefficient entrepreneur;

$p_{s b}^{2}$ : probability of success of contract 2 given that it is chosen by the inefficient entrepreneur;

$p_{1}^{g}$ : probability that the efficient type chooses contract 1 ;

$p_{2}^{g}$ : probability that the efficient type chooses contract 2;

$p_{1}^{b}:$ probability that the inefficient type chooses contract 1 ;

$p_{2}^{b}$ : probability that the inefficient type chooses contract 2;

$I$ : funding requirement;

$r$ : opportunity cost (\%) for the bank;

$U_{i}$ : opportunity cost (\%) for entrepreneur $i=\{g b\}$,

where ' $g$ ' is for efficient and ' $b$ ' is for inneficient.

$C M_{e}$ : contribution margin under the efficient performance contract 1;

$C M_{n}$ : expected contribution margin under the inefficient performance of the inefficient type by taking contract 2 ; $t_{s}^{e} / t_{a}^{e}$ : reward to agent for undertaking contract 1 under symmetric and asymmetric case, respectively;

$t_{s}^{n} / t_{a}^{n}$ : reward to agent for undertaking contract 2 under symmetric and asymmetric case, respectively;

$\alpha_{g}$ : probability that the entrepreneur is efficient.

Contract 1: normally should be chosen by an efficient agent, as it involves risky strategies and therefore high expected profits.

Contract 2: normally should be chosen by an inefficient agent, as it involves lower risky strategies and therefore lower expected profits.

We proceed by defining the sharing ratio to the agent under symmetric and asymmetric information. We, then, develop three types of adverse selection models. Finally we combine our developed indices with due diligence to minimize the effect of adverse selection.

2.1. The symmetric case. Under this scenario, the bank has full knowledge of the job prospects, as well as about the agent types. Therefore, the agent gets only her opportunity cost. Also we should remember that the bank exist in a perfectly competitive market and, therefore, its minimum aim is to break even:

$P_{s g}^{1} \cdot t_{s}^{e} \cdot C M_{e}=U_{g}$

$P_{s b}^{2} \cdot t_{s}^{n} \cdot C M n=U_{b}$.

Or alternatively for the bank to break even:

$P^{1}{ }_{s g} \cdot\left(1-t_{s}^{e}\right) \cdot C M_{e}=r . I$

$t_{s}^{e}=1-r . I /\left(P^{1}{ }_{s g} . C M_{e}\right)$

$P^{2}{ }_{s b} \cdot\left(1-t^{n}\right) \cdot C M_{n}=r . I$

$t_{s}^{n}=1-r . I /\left(P_{s b}^{2} . C M_{n}\right)$.

It is important to note that, in Islamic jurisprudence, the probability of success of a project should exceed $50 \%$, otherwise, we are committing "Gharar". This is not a requirement in the conventional system. So, even under symmetric information, projects might be turned down by Islamic banks if they are not exceeding this threshold. This, however, limits the number of projects to a safer set. On the other and, conventional banks are not concerned by this issue as long as their expected profits are greater than their opportunity cost.

2.2. The asymmetric case. In this scenario, the bank does not know the agent type and, therefore, estimates an expected profit from the contract chosen by the agent. Therefore, it needs to calculate the expected probability of success of each contract.

Put $m_{1}$ : probability of success of contract $1=$ $\alpha_{g} \cdot p^{g}{ }_{1} \cdot p_{s g}^{1}+\left(1-\alpha_{g}\right) p^{b}{ }_{1} \cdot p_{s b}^{1}$, 
$m_{2}$ : probability of success of contract $2=$

$\alpha_{g} \cdot p_{2}^{g} p_{s g}^{2}+\left(1-\alpha_{g}\right) p_{2}^{b} \cdot p_{s b}^{2}$.

In this case, the profit of the bank is

$m_{1} \cdot\left(1-t^{e}\right) \cdot C M_{e}-r . I$ from contract 1

$m_{2} \cdot\left(1-t^{n}{ }_{a}\right) \cdot C M_{n}-r . I$ from contract 2

While there is no restriction about the probability of success in the conventional system, it has to exceed $50 \%$ in Islamic jurisprudence. If it is less than $50 \%$, then, we fall in the concept of "Gharar" which is prohibited in Shari'a.

Under the asymmetric case, we have refined the Tirole (2006) probability of success in two ways. First, we allowed for a contract specific probability to each contract $\left(p_{s g}^{1} ; p_{s g}^{2} ; p_{s b}^{1} ; p_{s b}^{2}\right)$. Second, we allowed for the chance that a certain type of agent might or might not choose a certain type of contracts $\left(p_{1}^{g} ; p_{2}^{g} ; p_{1}^{b} ; p_{2}^{b}\right)$. This is very important under Islamic jurisprudence to refine the probability of success in order not fall below the 50\% threshold.

This is a double-sided effect concept. On the one hand, because there is no restriction on the probability of success of a project for conventional banks, they have a wider selection of projects compared to Islamic projects. On the other hand, because of this restriction, Islamic banks can only engage in fair risk projects.

We should remark as well that $m_{1}$ will tend to be lower than $p^{1}$. This is due to the fact that inefficient entrepreneurs pooling with efficient ones make the probability of success lower. This induces Islamic banks to engage less in riskier projects.

We should also remark that $m_{2}$ will tend to be higher than $p^{1}$. This is due to the pooling of efficient agents with bad ones. This, in turn, makes the probability of success of contract 2 higher. This induces Islamic banks to undertake less risky projects.

Under the asymmetric case, we have two cases:

\subsection{A. market breakdown.}

For contract 1:

$m_{1} . C M_{e}<$ r.I: No funding for contract 1

This is due to the fact that $m_{1}<m^{*}=r . I / C M e$, which means that if inefficient entrepreneurs are pooling with efficient types nobody gets funding. This situation is referred to as market breakdown (Tirole, 2006).

\section{For contract 2:}

$m_{2} . C M_{n}<$ r.I: no funding for contract 2 .

This is due to the fact that $m^{2}<m^{* *}=r . I / C M_{n}$. Here we should note that, because the efficient entrepreneur might have a very high probability of success for contract 2 (because it is easier for her compared to 1), this raises the threshold $(m)$ required too high. This, therefore, deprives the inefficient entrepreneur from taking contract 2 and makes it uninteresting for the efficient agent. This time because efficient entrepreneurs are pooled with inefficient ones nobody gets funding.

This represents another market breakdown.

\subsection{B. Funding and cross subsidization.}

If $m_{1} . C M_{e}>$ r.I: funding for contract $1 m_{2} . C M_{e}>$ r.I: funding for contract 2 .

In this case, the agent set her reward in consistency with the bank breaking even.

$m_{1} \cdot\left(1-t_{a}^{e}\right) \cdot C M_{e}=r . I \leftrightarrow t_{a}^{e}=1-r . I /\left(m_{2} \cdot C M_{e}\right)$

$m_{2} \cdot\left(1-t^{n}{ }_{a}\right) \cdot C M_{n}=r . I \leftrightarrow t^{n}{ }_{a}=1-r \cdot I /\left(m_{2} \cdot C M_{e}\right)$.

Now let's compare the transfer to the agents under both scenarios:

Contract 1: $t_{a}^{e}-t_{s}^{e}=U_{g .}\left(1 / m_{1}-1 / p^{1}{ }_{s g}\right)$

Contract 2: $t_{a}^{n}-t_{s}^{n}=U_{b} .\left(1 / m_{2}-1 / p_{s b}^{2}\right)$.

This can be either a gain or a loss to the agent from asymmetric information. In fact, the sign value of (9) and (10) depends on the values between parentheses.

In case we have different value signs from both contracts then we speak about "cross subsidization".

Also an additional contribution is that we can create a Perfect Cross Subsidization where the gain from one contract compensates for the loss from the other contract.

For a perfect cross subsidization to occur, we must have: $\left(t_{a}^{e}-t^{e}\right) \cdot C M_{e}=-\left(t^{n}{ }_{a}-t^{n}{ }_{s}\right) \cdot C M_{n}$.

Replacing " $t$ " $a$ " and " $t$ " ${ }_{a}$ " by their values in (7) and and (8) and putting $C M_{e}=K . C M_{n}$ we have:

$K=\left(1 / p^{1}{ }_{s g}-1 / m_{1}\right) /\left(1 / m_{2}-1 / p^{2}{ }_{s b}\right)$.

This should help in deciding about the multiplier factor $K$ to decide on the maximum and minimum contribution required from a project.

\section{Methodology}

To reduce the problem of adverse selection in Mudaraba contracts, we have tried to develop the Tirole (2006) projects privately known prospects model in four consecutive ways. First, we extended the model using a menu of two different contracts. Second, we allowed for specific probabilities of contract success given a specific agent type. Third, we tried to make the model Shari'a compliant; and fourth, combine the model with an adverse selection index and due diligence. 


\subsection{The model assumptions.}

- Banks and entrepreneurs are risk neutral and rational.

- No collateral is required as in the Mudaraba financing.

- No intervention from the bank in the running of the business.

- The opportunity cost of the entrepreneur $\left(U_{i}\right)$ represents what they can get in conventional system. The opportunity cost of the bank r.I is what the bank can get if it does not undertake the project.

- Projects are Shari'a complaints.

Minimum and maximum values of project's contribution margin can be determined through the banks relevant means.

We will proceed by the treatment of the condtions of no adverse selection. Then, we develop three adverse selection indices: "Mimicking Likelihood Index (MLI), Relative Adverse selection Index (RAS index).

\section{Results and discussion}

4.1. Condition for "no adverse selection". Our specific probability treatment will allow us to identify whether there is a likelihood scenario that one type (efficient/inefficient) might mimic the other. We can proceed in the following manner:

For the "efficient type" to choose contract 1, we must have contract 2 less appealing to her.

i.e.: $p_{s g}^{1} \cdot t_{a}^{e} \cdot C M_{e}>p_{s g}^{2} \cdot t_{a}^{n} \cdot C M_{n}+p_{s g}^{1} \cdot C M_{e}-p_{s g}^{2} \cdot C M_{n}$

Replacing $t_{a}^{e}$ and $t_{a}^{n}$ by their optimum values in (7) and (8), we must have:

$p_{s g}^{2} / p_{s g}^{1}>m_{2} / m_{1}$

For the inefficient type not to "mimic" the efficient one, we must have contract 1 less appealing to her. i.e.:

$p_{s b}^{2} \cdot t_{s}^{n} \cdot C M_{n}>p_{s g}^{2} \cdot t^{n} \cdot C M_{n}+p_{s g}^{1} \cdot C M_{e}-p_{s g}^{2} \cdot C M_{n}$.

Replacing $t_{a}^{e}$ and $t_{a}^{n}$ by their optimum values from

(7) and (8), we must have:

$p_{s b}^{2} / p_{s b}^{1}<m_{2} / m_{1}$.

So, for no type to mimic, the other we must have the following condition:

$p_{s b}^{2} / p_{s b}^{1}<m_{2} / m_{1}<p_{s g}^{2} / p_{s g}^{1}$

This should prove very useful for Islamic banks. In fact, only through a proper probability appraisal the bank can decide whether there is a case of adverse selection.
4.2. "Mimicking Likelihood Index (MLI)". One of the issues a bank can face is which type has more of a tendency to mimic the other. Knowing this can help the bank to decide which contract is worthy of more control than the other. Taking the base index as 1 , we can develop a measure that shows the likelihood of a certain type to mimic the other.

$\operatorname{MLI}($ inefficient $)=1+\left(P_{s b}^{2} / p_{\mathrm{sb}}^{1}-m_{2} / m_{1}\right) /\left(m_{2} / m_{1}\right)(15)$

$M L I$ (inefficient $)=1+\left(P_{s b}^{2} / p^{1}{ }_{s b}-m_{2} / m_{1}\right) /\left(m_{2} / m_{1}\right)(16)$

For inefficient type to "mimic" the efficient type, index (Inefficient type) must be more than 1.

For efficient type to "mimic" the inefficient type, index (efficient type) must be less than 1. This measures proves to be useful in deciding about which type is worthy of more focus than the other.

4.3. Relative adverse selection index $\left(\operatorname{RAS}_{\text {(index) }}\right)$. Relative adverse selection index (RAS index). In our case, the inefficient type should normally select contract 2, and the efficient should choose contract 1 . Using our $R A S_{\text {(index) }}$, we can figure out which type of entrepreneurs has more tendency than the other to select a non-compatible contract for her type:

$R A S_{(\text {index })}=\operatorname{MLI}($ inefficient $) / M L I$ (efficient).

$\mathrm{n}$ this case, if $R A S_{(\text {index })}>1$ more tendency for inefficient type to select $\mathrm{C}_{1}$ than efficient type selecting $\mathrm{C}_{2}, R A S_{(\text {index) }}<1$ more tendency for efficient type to select $\mathrm{C}_{2}$ than inefficient type selecting $\mathrm{C}_{1}$.

This measure will be useful in identifying which type of agents is worthy of more focus than the other. For example, if $R A S$ (index) $>1(<1)$, then, we should introduce some controlling mechanisms in order to deprive the inefficient (efficient) type from selecting contract 1 (2).

4.4. Measure of "adverse selection" index. As in Tirole (2006), we try to develop an index of adverse selection. Our main difference is that we develop an index for each type of contract with additional agent specific probabilities.

- Contract 1: the condition $m_{1} \cdot C m_{e}>$ r.I can be restated in its original form:

$\left(\alpha_{g} \cdot p^{g}{ }_{1} \cdot p_{s g}^{1}+\alpha_{b} \cdot p^{b} \cdot p_{s b}^{1}\right) \cdot C m_{e}>r . I$ after a mathematical manipulation:

$\left\{1+\left[-\left(1-\alpha_{g}\right)\left(p^{g}{ }_{1} p^{1}{ }_{s g}-p^{b}{ }_{1} \cdot p_{s b}^{1}\right) /\left(p^{g}{ }_{1} \cdot p^{1}{ }_{s g}\right)\right]\right\}$.

$p^{g}{ }_{1 .} p_{s g}^{1}>$ r.I $/ C m e$

The term

$\left[-\left(1-\alpha_{g}\right)\left(p^{g}{ }_{1} p_{s g}^{1}-p_{1}^{b} \cdot p_{s b}^{1}\right) /\left(p^{g}{ }_{1} \cdot p_{s g}^{1}\right)\right]$

represents our adverse selection index for contract 1 .

Intuitively, the higher is this term, the higher will be the term on the left hand side of (17). This means 
that the bank will be "mistakenly" motivated to extend credit for contract 1. We said "mistakenly", because the increase in the probability of success is meant to be due to the efficient entrepreneurs and not to the inefficient ones. If this happens, then, we have a clear case of "adverse selection". As we can see, this index is affected mainly by two elements:

$\left(1-\alpha_{g}\right)$ : the probability of the inefficient entrepreneur and

$\left(p^{g}{ }_{1} p^{1}{ }_{s g}-p^{b}{ }_{1} \cdot p^{1}{ }_{s b}\right) /\left(p^{g}{ }_{1} \cdot p^{1}{ }_{s g}\right)$.

The likelihood ratio:

- Contract 2: the condition $m_{2} . C M_{n}>$ r.I can be restated in its original form as:

$\left(\alpha_{g} \cdot p^{g} 2 p_{s g}^{2}+\left(1-\alpha_{g}\right) \cdot p_{2}^{b} \cdot p_{s b}^{2}\right) \cdot C M_{n}>$ r.I.

Similarly to contract 1 , this condition can be restated as:

$\left\{1+\left[-\left(\alpha_{g}\right) \cdot\left(p_{2}^{b} \cdot p_{s b}^{2}-p_{2}^{g} p_{s g}^{2}\right) /\left(p_{2}^{b} \cdot p_{s b}^{2}\right)\right]\right\} \cdot P_{s b}^{2}$

$p_{2}^{b}>r . I$

The same reasoning applied to contract 1 can be applied to contract 2, i.e., the term:

$\left[-\left(\alpha_{g}\right) \cdot\left(p_{2}^{b} \cdot p_{s b}^{2}-p_{2}^{g} p_{s g}^{2}\right) /\left(p_{2}^{b} \cdot p_{s b}^{2}\right)\right]$

is the adverse selection index for contract 2 .

\section{Conclusion}

In this research, we have developed an adverse selection model using a two contract menu. For each contract, we developed three adverse selection indices. This methodology can prove to useful for Islamic banks facing Mudaraba financing. In fact, the more we can measure the extent of adverse selection the more Islamic banks can decide on the amount of due diligence required. This should prove very useful as a cost saving mechanism for Islamic banks. In fact, they can direct their due diligence efforts towards the contracts with the highest asymmetric information. To test the validity of such claim, we propose the extension of this model to incorporate due diligence.

To reduce asymmetric information, this research can be extended in different ways. First, introduce third party hedging. For example, testing whether the incorporation of a bank in a supplier-corporation framework can improve efforts from a corporation.

A second venue is improving the adverse selection index itself by improving information about the model probabilities. This can be achieved by applying game theoretical models under imperfect information. One such approach is the Harsanyi model. Under the same framework how about if we introduce a menu where the agent can, rather than forced to, choose between two contract types? In other words, can menu offering of two contracts be the ultimate solution for agent's types' separation.

Another venue of extension is to introduce risk perception (loving or aversion) from both the bank and the agent.

The model is for a one stage game. We can, then, extend this model over more than one period of time.

The bank's due diligence of the Mudaraba project can often suffer from many anomalies such as errors in the technical appraisal of projects by the due diligence or dishonesty of the due diligence team. So, there is a need to extend such models by taking into account ways to improve upon such shortcoming.

Other venues can introduce mechanism design to induce the agent to select an appropriate type of contracts.

\section{References}

1. AAOIFI (2003). Sharia' standards. Kingdom of Bahrain.

2. Al-Jarhi, M.A., Iqbal, M. (2001). Islamic banking: Faqs. Occasional Paper 4.

3. Al-Suwailem, S. (2006). Hedging in Islamic finance. Islamic Development Bank, Islamic Research and Training Institute.

4. Bacha, O.I. (1997). Adapting mudarabah financing to contemporary realities: a proposed financing structure.

5. Berger, A.N. Frame, W.S., Ioannidou, V. (2011). Tests of ex-ante versus ex-post theories of collateral using private and public information, Journal of Financial Economics, 100(1), pp. 85-97.

6. Bernheim, B.D., Wantz, A. (1992). A tax-based test of the dividend signaling hypothesis. Tech. rep., National Bureau of Economic Research.

7. Besanko, D., Thakor, A.V. (1987). Collateral and rationing: sorting equilibria in monopolistic and competitive credit markets, International Economic Review, pp. 671-689.

8. Bester, H. (1985). Screening vs. rationing in credit markets with imperfect information, The American Economic Review, pp. 850-855.

9. Brealey, R., Leland, H.E., Pyle, D.H. (1977). Informational asymmetries, financial structure, and financial intermediation, The Journal of Finance, 32(2), pp. 371-387.

10. Brown, M., Zehnder, C. (2010). The emergence of information sharing in credit markets, Journal of Financial Intermediation, 19(2), pp. 255-278.

11. Chapra, M.U., Khan, T. (2000). Regulation and supervision of Islamic banks. Islamic Development Bank, Islamic Research and Training Institute Jeddah. 
12. Chemmanur, T.J., Fulghieri, P. (1994). Reputation, renegotiation, and the choice between bank loans and publicly traded debt, Review of Financial Studies, 7(3), pp. 475-506.

13. Gafoor, A.A. (2001). Mudaraba-based investment and finance. Accessed at 11.03. 2013.

14. Gehrig, T., Stenbacka, R. (2007). Information sharing and lending market competition with switching costs and poaching, European Economic Review, 51(1), pp. 77-99.

15. Gompers, P., Lerner, J. (1999). An analysis of compensation in the us venture capital partnership, Journal of Financial Economics, 51(1), pp. 3-44.

16. Karim, A.A. (2015). An incentive-compatible constraints for Islamic banking: some lessons from bank muamalat, Islamic Banking and Finance, 95.

17. Khalil, A.-F.A., Rickwood, C., Murinde, V. (2002). Evidence on agency-contractual problems in mudarabah financing operations by Islamic banks, Islamic Banking and Finance: New Perspectives on Profit Sharing and Risk, 57.

18. Khan, W.M. (1985). Towards an interest-free Islamic economic system. The Islamic Foundation, Leicester \& International Association for Islamic Economics, Islamabad, 84.

19. Landier, A., Thesmar, D. (2003). Financial contracting with optimistic entrepreneurs: theory and evidence. In: AFA 2004 San Diego Meetings.

20. Manove, M., Padilla, A.J., Pagano, M. (2001). Collateral versus project screening: a model of lazy banks, Rand Journal of Economics, pp. 726-744.

21. Mehri, M., Jouaber, K. (2012). A theory of profit sharing ratio under adverse selection: the case of Islamic venture capital.

22. Mutalip, A.L.A., Lutfi, A. (2009). Islamic venture capital and private equity: legal issues and challenges. Global Financial Services and Islamic Banking, Azmi \& Associates. 